\title{
Experience-Dependent Inhibitory Plasticity Is Mediated by CCK + Basket Cells in the Developing Dentate Gyrus
}

\author{
Ting Feng, Christian Alicea, Vincent Pham, Amanda Kirk, and Simon Pieraut \\ Department of Biology, University of Nevada, Reno, Nevada 89557
}

Early postnatal experience shapes both inhibitory and excitatory networks in the hippocampus. However, the underlying circuit plasticity is unclear. Using an enriched environment (EE) paradigm during the preweaning period in mice of either sex, we assessed the circuit plasticity of inhibitory cell types in the hippocampus. We found that cholecystokinin (CCK)-expressing basket cells strongly increased somatic inhibition on the excitatory granular cells (GCs) following EE, whereas another pivotal inhibitory cell type, parvalbumin (PV)-expressing cells, did not show changes. Using electrophysiological analysis and the use of cannabinoid receptor 1 (CB1R) agonist WIN 55212-2, we demonstrate that the change in somatic inhibition from CCK+ neurons increases CB1R-mediated inhibition in the circuit. By inhibiting activity of the entorhinal cortex (EC) using a chemogenetic approach, we further demonstrate that the activity of the projections from the EC mediates the developmental assembly of CCK + basket cell network. Altogether, our study places the experience-dependent remodeling of CCK + basket cell innervation as a central process to adjust inhibition in the dentate gyrus and shows that cortical inputs to the hippocampus play an instructional role in controlling the refinement of the synaptic connections during the preweaning period.

Key words: dentate gyrus; development; GABAergic; interneuron; plasticity; synapse

\section{Significance Statement}

Brain plasticity is triggered by experience during postnatal brain development and shapes the maturing neural circuits. In humans, altered experience-dependent plasticity can have long-lasting detrimental effects on circuit function and lead to psychiatric disorders. Yet, the cellular mechanisms governing how early experience fine-tunes the maturing synaptic network is not fully understood. Here, taking advantage of an enrichment-housing paradigm, we unravel a new plasticity mechanism involved in the maintenance of the inhibitory to excitatory balance in the hippocampus. Our findings demonstrate that cortical activity instructs the assembly of the CCK + basket cell network. Considering the importance of this specific cell type for learning and memory, experience-dependent remodeling of $\mathrm{CCK}+$ cells may be a critical determinant for establishing appropriate neural networks.

\section{Introduction}

Early postnatal development is a critical period during which most synapses are formed. At this time, early sensory stimulations are critical for proper circuit maturation and can have a long-lasting deleterious effect on sensory processing as well as on complex cognitive functions when compromised (Cancedda et

Received May 16, 2020; revised Apr. 13, 2021; accepted Apr. 16, 2021.

Author contributions: T.F. and S.P. designed research; T.F. and S.P. performed research; T.F., C.A., V.P., A.K., and S.P. analyzed data; V.P. contributed unpublished reagents/analytic tools; and S.P. wrote the paper.

This work was supported by Startup funds from the University of Nevada, Reno and by the National Institute of General Medical Sciences of the National Institutes of Health Grant P20 GM103650 to S.P. and the Cellular and Molecular Imaging Core facility supported by the National Institute of General Medical Sciences of the National Institutes of Health Grant P20 GM103650. We thank Dr. Jung Hwan Kim for comments and feedback and Cynthia Lee, Aizel Nadonga, Catherine Bonuel, and Blake Sieck for assistance with the mouse colony, genotyping, and cloning of adeno-associated viral vectors.

The authors declare no competing financial interests.

Correspondence should be addressed to Simon Pieraut at spieraut@unr.edu.

https://doi.org/10.1523/JNEUROSCI.1207-20.2021

Copyright $\odot 2021$ the authors al., 2004; Sale et al., 2004; Nabel and Morishita, 2013; Kalogeraki et al., 2017). Neuronal activity plays a critical role in regulating experience-dependent plasticity and in fine-tuning neural circuits originally assembled under the control of genetic programs. Preweaning enrichment $(\mathrm{PE})$, that is, when pups are raised with their mother from birth to weaning time, offers a valuable model to study the cellular mechanisms underlying experience-dependent remodeling of nascent neural circuits. Studies using PE found significant alterations in the synaptic network of the dentate gyrus (DG) in the hippocampus. Electrophysiology data demonstrate an increase in excitatory and inhibitory drives in juvenile mice raised in an enriched environment (EE) during this preweaning period (Liu et al., 2012; Hosseiny et al., 2015). At the structural level, increased spine density is consistently found on the dendrites of excitatory granular cells (GCs), suggesting that the increase in the excitatory drive is because of an increased number of synapses formed by the afferents from the entorhinal cortex layer 2 (EC2) onto GC dendrites (Liu et al., 2012; Hosseiny et al., 2015). However, the underlying cellular and 
circuit mechanism of the increased inhibitory drive is not known. In particular, the involvement of specific populations of inhibitory synapses in this plasticity has not been explored. This question is challenging because diverse classes of inhibitory interneurons innervate the DG. The well-established inhibitory cell types that have been described in the cortical and other hippocampal circuits have also been characterized in the DG (Hosp et al., 2014; Pelkey et al., 2017). Interestingly, each inhibitory cell type projects its axons to distinct laminae, where they target specific subdomains along the somatodendritic axis of principal excitatory GCs. This unique connectivity rule enables pattern separation, a process by which the rich and overlapping multimodal inputs from the entorhinal cortex are decorrelated into a sparse and specific output pattern (Bel et al., 2015; Lee et al., 2016; Szabo et al., 2017; Espinoza et al., 2018; Barak et al., 2019; Madar et al., 2019). This computation is critical for information coding in the hippocampus and for memory indexation and retrieval (Deng et al., 2013; Kesner et al., 2016). Understanding how the GABAergic synaptic network is shaped by postnatal experience can inform how the computations in the hippocampus are established during this period of dramatic connectivity change. Do all inhibitory cell types indistinctly form more synapses when animals are raised in EE, or are there specific cell types responsible for the increased inhibitory drive?

To address these questions, we measured the synaptic densities from distinct populations of inhibitory neurons in PE mice. We found that enriched postnatal experience has a strong impact on the number of cholecystokinin (CCK)-expressing basket cell (BC) inputs on GC soma. In contrast, innervation from parvalbumin (PV)-expressing cells was unaffected. Inputs from CCK$\mathrm{BC}$ are strongly modulated by an endocannabinoids signaling that temporary blocks GABA release at their terminals. We found that this process, called depolarized-induced suppression of inhibition (DSI), is increased in mice raised in an EE. By combining our enrichment paradigm with a chemogenetic approach, we demonstrate that projection neuron activity in EC2 is instructive for the CCK-BC synaptic network assembly. Altogether, our work brings new insight into how specific inhibitory cell types undergo structural rearrangement in response to the changes in cortical activity and how it affects the modality of inhibition in the circuit.

\section{Materials and Methods}

Animal husbandry and EE raising. All animal procedures were approved by the University of Nevada, Reno Institutional Animal Care and Use Committee and were in accordance with federal guidelines. All experiments were performed on both male and female C57BL/6 mice, before weaning, at postnatal days 19-21. All mice were exposed to a $12 \mathrm{~h}$ light/12 h dark cycle with food and water provided ad libitum. For preweaning enrichment, pregnant female mice at embryonic days 16-19 (E16-19) were randomly assigned to an enrichment housing cage 4-7 d before delivery with another female companion. The EE cage consists of a large Plexiglas laboratory cage $(60 \times 45 \times 20 \mathrm{~cm})$ containing objects of various shapes, colors, and textures, including a plastic house, tunnels, wood blocks, and a running wheel. The different objects and position were rearranged every other day to maximize novelty. All pups assigned to the PE group were raised in EE cages from birth to juvenile, whereas the pups that were referred to standard housing $(\mathrm{SH})$ were placed with their female breeder in standard control cages. The number of pups per litter was kept constant ( 5 or 6 pups) for every experiment to avoid confounding effect because of litter size.

Acute slice preparation. Transverse hippocampal slices were prepared from C57BL/6L (P19-21). Animals were anesthetized with isoflurane and decapitated. The cerebral hemispheres were removed and bathed for $1 \mathrm{~min}$ in a cold ice slushy sucrose-based dissection buffer containing the following (in mM): $87 \mathrm{NaCl}, 25 \mathrm{NaHCO} 3,1.25 \mathrm{Na}_{2} \mathrm{HPO}_{4}, 2.5$ $\mathrm{KCl}, 7 \mathrm{MgCl} 2,10$ glucose, $0.5 \mathrm{CaCl} 2,1.3$ ascorbic acid, 75 sucrose, and equilibrated with $95 \% \mathrm{O}_{2} / 5 \% \mathrm{CO}_{2}$. Horizontal slices ( $300 \mu \mathrm{m}$ thickness) were cut with a VF $300-0 \mathrm{Z}$ microtome (Precisionary) and transferred to a recovery chamber with modified artificial cerebrospinal fluid (ACSF) consisting of the following (in $\mathrm{mm}$ ): $92 \mathrm{NaCl}, 30 \mathrm{NaHCO} 3,1.2$ $\mathrm{Na}_{2} \mathrm{HPO}_{4}, 2.5 \mathrm{KCl}, 0.5 \mathrm{CaCl} 2,10 \mathrm{MgSO}_{4}, 25$ glucose, 20 HEPES, 5 ascorbic acid, 2 Thiourea, and three sodium pyruvic, oxygenized with $95 \%$ $\mathrm{O}_{2} / 5 \% \mathrm{CO}_{2}$. Slices were recovered for $30 \mathrm{~min}$ at $32-34^{\circ} \mathrm{C}$ and moved to room temperature for recovering another $30 \mathrm{~min}$ before recording and were then maintained at room temperature for the duration of the experiment $(4-6 \mathrm{~h})$.

Electrophysiology and pharmacology. All recordings were performed in the outer GC layer with a SutterPatch Double IPA Amplifier (Sutter Instrument). Signals were acquired using SutterPatch software (Sutter Instrument), filtered at $5 \mathrm{kHZ}$ and sampled at $10 \mathrm{kHz}$. During the recording, slices were maintained in oxygenized standard ACSF, containing the following (in mM): $124 \mathrm{NaCl}, 24 \mathrm{NaHCO} 3,1.2 \mathrm{Na}_{2} \mathrm{HPO}_{4}, 2.5 \mathrm{KCl}, 2$ $\mathrm{CaCl} 2,2 \mathrm{MgSO}_{4}, 12.5$ glucose, and 5 HEPES. For inhibitory postsynaptic current (IPSC) recordings, neurons were clamped at $-70 \mathrm{mV}$, using glass pipettes (resistance 3-5 $\mathrm{m} \Omega$ ) filled with a high chloride internal solution containing the following (in mM): $135 \mathrm{CsCl}, 4 \mathrm{MgCl} 2,0.1 \mathrm{EGTA}, 10$ HEPES, $10 \mathrm{Na}$-phosphocreatine, $2 \mathrm{Mg}$-ATP, $0.3 \mathrm{Na}$-GTP, and 5 QX314 , pH 7.4, adjusted with $\mathrm{KOH}$ to $290-295$ mOsm. D-AP5 (Tocris Bioscience) at $50 \mu \mathrm{m}$ and CNQX (Tocris Bioscience) at $10 \mu \mathrm{m}$ were added to ACSF to block NMDA and AMPA, respectively. To record miniature IPSC (mIPSC), Tetrodotoxin (TTX; Enzo Life Sciences) at 1 $\mu \mathrm{M}$ was applied in the bath to block $\mathrm{Na}^{+}$currents. For evoked IPSC (eIPSC), synaptic basket cell inhibitory current was evoked by extracellular stimulation in the matured GCs layer using a theta-glass pipette connected to the 2100 Isolated Pulse Stimulator $(100 \mu \mathrm{s} / 200 \mu \mathrm{A} ; \mathrm{A}-\mathrm{M}$ Systems). Each paired pulse trial consisted of three consecutive responses at $15 \mathrm{~s}$, including 5 different interpulse intervals (IPI; see Fig. $4 F$ ). For miniature excitatory postsynaptic current (mEPSC) recordings, the GCs were patched with the pipette filled with an internal solution containing the following (in mM): 122.5 Gluconic acid, $10 \mathrm{CsCl}, 122.5 \mathrm{CsOH}, 5$ $\mathrm{NaCl}, 1.5 \mathrm{MgCl}$, 5 HEPES, 1 EGTA, $10 \mathrm{Na}$-phosphocreatine, $3 \mathrm{Mg}$ ATP, 0.3 Na-GTP, and 5 QX-314, pH 7.3, adjusted with CsOH to 290$295 \mathrm{mOsm}$. Neurons were held at $-70 \mathrm{mV}$ in the presence of $50 \mu \mathrm{M}$ picrotoxin (Tocris Bioscience) to block GABA synaptic currents and $1 \mu \mathrm{M}$ TTX. Neurotransmitter release from CCK inhibitory interneurons was pharmacologically blocked by bath application of $\omega$-conotoxin GVIa ( 1 $\mu \mathrm{M}$; Sigma Laboratories and Alomone Laboratories) and the CB1 receptor agonist, WIN 55212-2 (WIN; $5 \mu \mathrm{M}$; Sigma Laboratories). For the DSI experiment, spontaneous IPSC was recorded in acute brain slices with carbachol ( $5 \mu \mathrm{M}$; Millipore Sigma). DSI was induced by depolarizing GCs with a $1 \mathrm{~Hz}$ train from $-70 \mathrm{mV}$ to $0 \mathrm{mV}$ for $8 \mathrm{~s}$. DSI magnitude is calculated using the following formula as the percentage of the decrease of the charge transfer normalized to time after the train: DSI magnitude $(\%)=100^{*}$ [1-charge transfer/20 s (baseline)/charge transfer/ $15 \mathrm{~s}$ (after DSI induction; Wilson and Nicoll, 2001; Kim et al., 2002)].

Virus production and injection. The padeno-associated virus-hSynhM4D(Gi)-mCherry was a gift from Bryan Roth (viral prep, catalog \#50475-AAV2, Addgene). The virus consists of a human truncated promoter driving the expression of $\mathrm{hM} 4 \mathrm{D}(\mathrm{Gi})$ fused to its C-terminal to mCherry (Krashes et al., 2011). The titer of the virus was $5 \times 10^{12}$ viral genomic particles/ml. AAV-hSyn-GFP-Gephyrin were generated with a capsid DJ and purified in our laboratory by a protocol described in Mcclure et al. (2011). The human Synapsin promoter drives the expression of GFP fused to the $\mathrm{N}$ terminal of gephyrin. The viral titer was 2 $\times 1012 \mathrm{GC} / \mathrm{ml}$, as determined by quantitative PCR. For neonatal in vivo infections, pups were anesthetized on ice and injected with $0.5 \mu \mathrm{l}$ of the viral stock using a glass micropipette $(10 \mu \mathrm{m}$ tip diameter). Pups were then warmed up for $5 \mathrm{~min}$ on a heating pad and returned to home cages until experiments. The viruses encoding GFP-Gephyrin were delivered into the cerebral lateral ventricles to target GCs in the DG (Pieraut et al., 2014). Using the stereotaxic manipulator, the tip of the pipette was placed above $\lambda$ to set the 0 for both $\mathrm{X}$ and Y coordinates. Then, the 
A<smiles>C1CCCC1</smiles>

or

Standard housing $(\mathrm{SH})$

B mEPSC

SH

PE
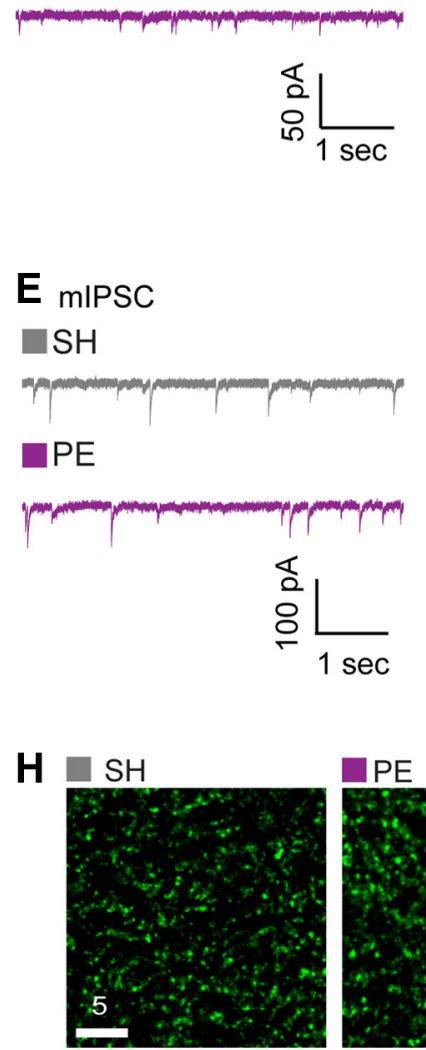

Pre-weaning enrichment (PE)
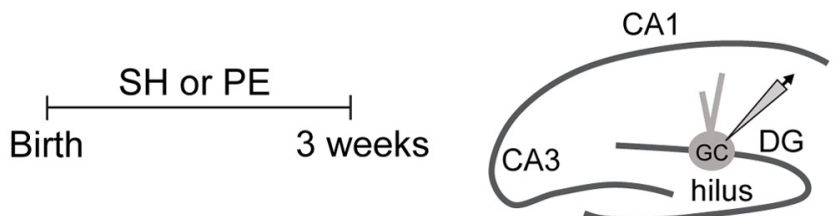
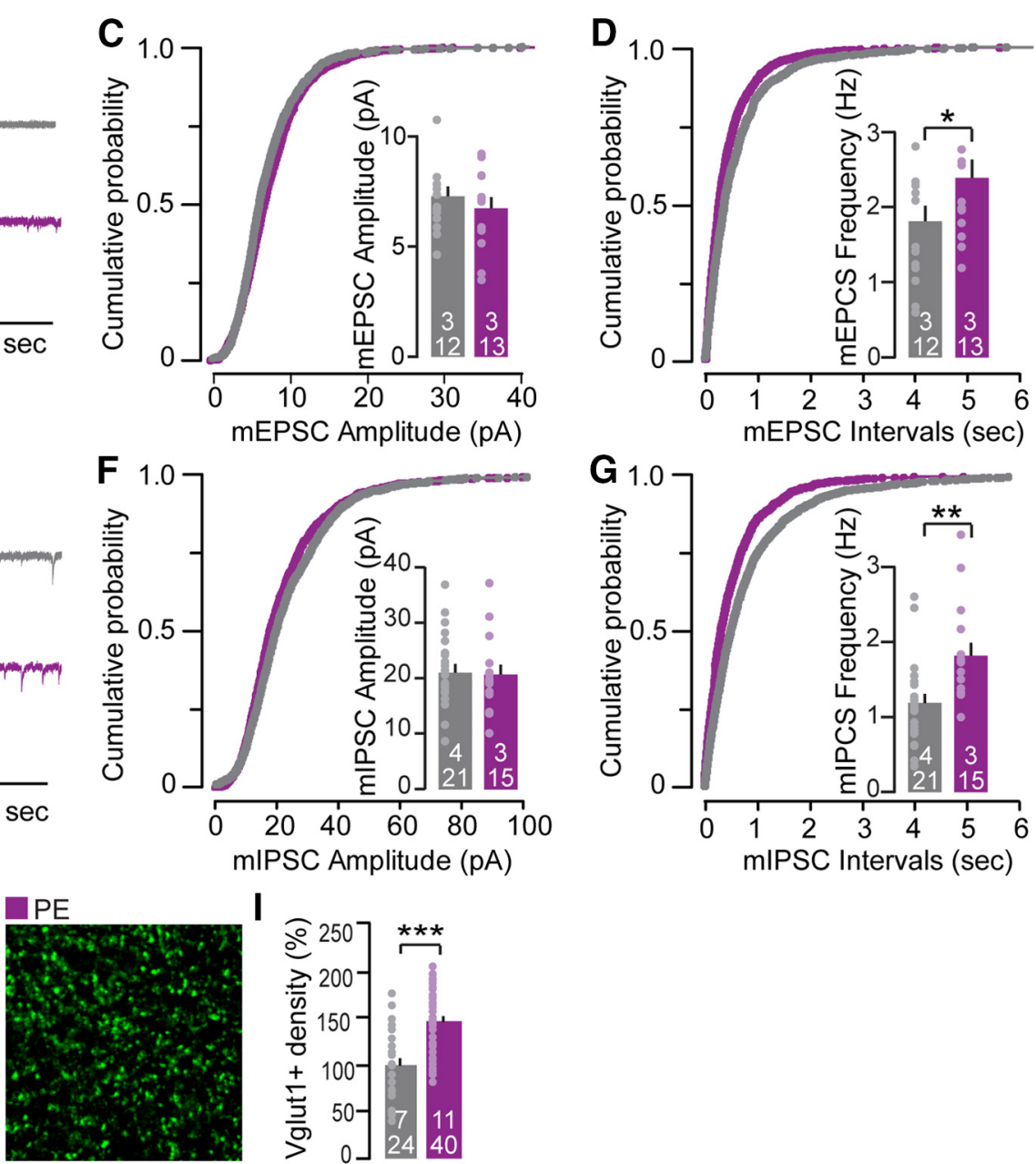

Figure 1. PE increases inhibitory and excitatory drive in the DG. $A$, Illustration of the SH and PE. Mice were raised either in SH or PE for 3 weeks after birth. Schematic illustration of the hippocampus with a representative whole-cell patch clamp recording of a granule cells in the DG. $\boldsymbol{B}$, Representative mEPSC traces recorded from mature GCS (P19-21) in acute brain slice from SH and PE. C, D, Cumulative distribution of the interevent intervals $(\boldsymbol{C})$ and amplitude $(\boldsymbol{D})$ of the mEPSC recorded in GCs from SH and PE (P19-P21). Insets, Mean frequency and amplitude. $* p<$ 0.05 by a two-sample $t$ test, $S H: a / n=3 / 12, P E:$ a $/ n=3 / 13$. $E-G$, Same as $\boldsymbol{B}$ to $\boldsymbol{D}$ but for mIPSC. Insets: mean frequency and amplitude; $* * p<0.01$ by a two-sample $t$ test, SH: a/n $=4 / 21$, PE: a/n =3/15. $\boldsymbol{H}$, Representative images of excitatory synaptic terminals labeled with antibodies against VGLUT1 (green) in the ML. I, Quantification of VGLUT1 puncta in the ML of brain section from mice raised in SH (3-4 hemispheres from a total of 7 mice) and PE mice (3-4 hemispheres from a total of 11 mice). PE data were normalized to SH control. Statistical comparisons were performed with a two-sample $t$ test $(* * * p<0.001)$. Data represent mean \pm SEM. The number of animals and images used are reported within each bar (a/n). All scale bars in $\mu \mathrm{m}$.

stereotaxic arms were moved to $(\mathrm{X}, \mathrm{Y})=(1.0,1.5) \mathrm{mm}$ for $\mathrm{P} 1$ pups. The pipette was inserted into the brain at the depth of $1.5 \mathrm{~mm}$ from the skull. For infection of pyramidal neurons with hM4Di-mCherry in the entorhinal cortex, pups were laid on one side and the pipette was inserted at $1 \mathrm{~mm}$ depth near the bottom of each ear (Pieraut et al., 2014). In this case, expression was restricted to superficial layers of the medial EC. The virus targeting specificity was confirmed in every experiment by imaging mCherry reporter.

Manipulation of perforant path with designer receptors exclusively activated by designer drugs. To manipulate perforant path (PP) fibers in the DG, juvenile mice were previously injected with pAAV-hSyn-hM4D (Gi)-mCherry at P1. From P15 to P21, mice received twice daily (9:00 A. M. and 7:00 P.M.) intraperitoneal (IP) injection of either saline (control) or $2.5 \mathrm{mg} / \mathrm{kg}$ Clozapine-N-oxide (CNO) solution. Following injection, the juvenile mice were put back with their female breeder. Body weight was monitored every day.

Immunohistochemistry. Mice were anesthetized with isoflurane and perfused with an ice-cold solution containing $4 \%$ paraformaldehyde. Brains were postfixed overnight in $1 \%$ paraformaldehyde and sliced in PBS using a vibratome. The $90-\mathrm{mm}$-thick brain sections were blocked in $4 \%$ BSA and $0.2 \%$ Triton X-100 in PBS at room temperature for $2 \mathrm{~h}$. Sections were then incubated with primary antibodies overnight at $4{ }^{\circ} \mathrm{C}$ in blocking solution, washed three times in PBS, incubated in speciesmatched fluorescently labeled secondary antibodies, and washed three times again. Slices were mounted with Invigtrogen SlowFade gold antifade reagent (catalog \#S36936, Fisher Scientific) for analysis. Primary 


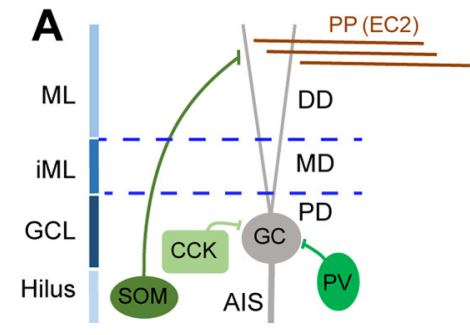

C

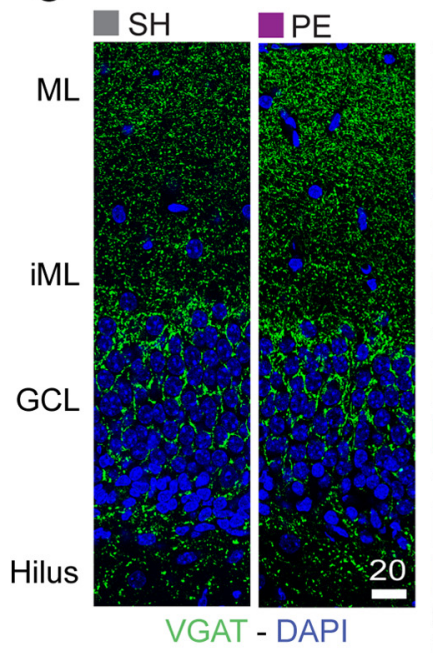

E

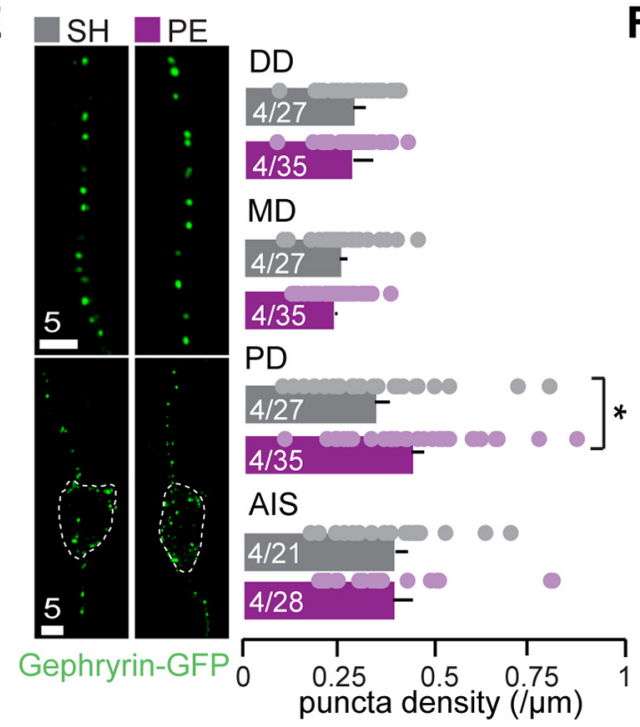

B

VGAT in hilusı
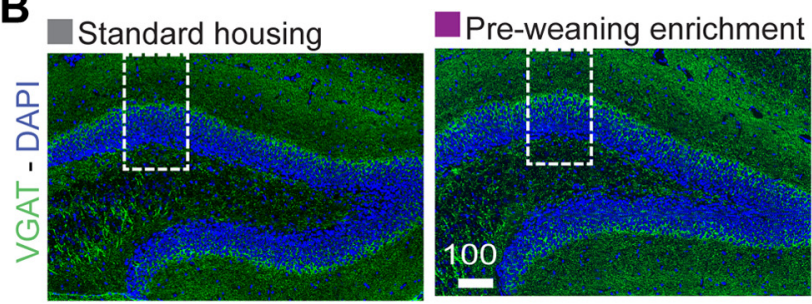

D

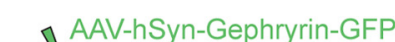

AAV-Ef1 $\alpha$-tdT-F
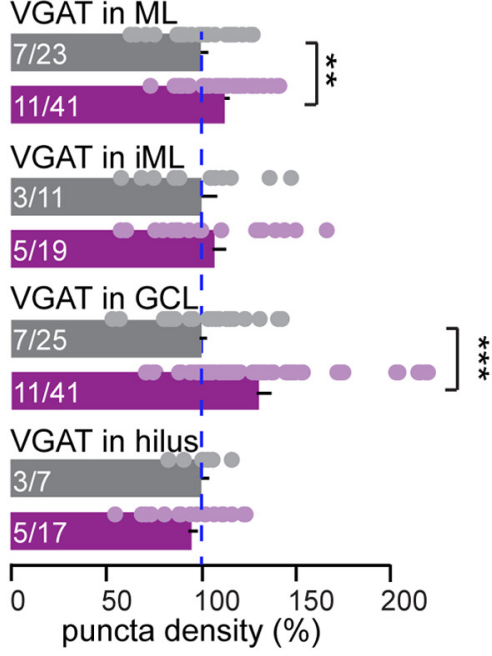

$\mathbf{F}$

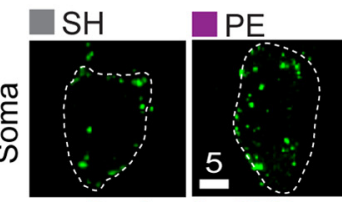

Gephryrin-GFP

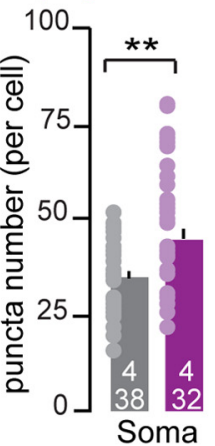

Figure 2. PE induces a perisomatic increase of inhibitory synapses on GCS. $\boldsymbol{A}$, Schematic representation of interneuron connectivity in the DG. PP(EC2), Projection from layer 2 entorhinal cortex neurons; PV, parvalbumin interneuron; CCK, cholecystokinin interneuron; SOM, somatostatin interneuron. Dendrites are segmented based on their location within the different laminae; distal dendrites (DD) in the ML, medial dendrites (MD) in the inner ML, proximal dendrites (PD) in the GC layer (GCL) and axon initial segment (AIS) in the hilus. $\boldsymbol{B}$, Confocal images of the DG from SH (left) and PE (right) mice stained with anti-VGAT (green) antibody and DAPI (blue). Box with dashed line indicates the region acquired at high magnification for VGAT puncta density quantification. $\mathbf{C}$, Left, representative images of the VGAT labeling for SH and PE mice. Right, quantification of VGAT puncta density in all laminae of the DG. Non-normalized data are presented in Table 1. D. Top, Schematic of dual AAV injection with AAV-hSyn-Gephyrin-GFP (green) and AAV-Ef1 $\alpha$-tdT-F in neonatal pups at P1. Bottom, Tracing and segmentation of GC dendrites tracing with Imaris is performed using anatomic cue (GC nuclei) as well as with the help of the labeling of EC2 fibers with tdT-F to localize the separation between inner and outer molecular layer (iML and ML). $\boldsymbol{E}$, Representative images of gephyrin-GFP fluorescence along the somatodendritic axis of GCs from SH and PE mice. Dashed lines represent the contour of the cell soma. The quantifications of the density of GFP clusters along the segments of the dendrites and the AIS are reported as number of clusters per $\mu$ m. Data are presented in Table 2. $\boldsymbol{F}$, Representative images of GC soma labeled with gephyrin-GFP and quantification of the number of cluster per soma. Data represent mean \pm SEM. Statistical comparison between SH and PE in individual layer or segment was performed by a two-sample $t$ test; ${ }^{*} p<0.05,{ }^{* *} p<0.01$, and ${ }^{* * *} p<0.001$. Data represent mean \pm SEM. The number of animals and images used are reported within each bar (a/n). All scale bars in $\mu$ m.

antibodies used were the following: rabbit antivesicular glutamate transporter 1(VGlut1; 1:1000; catalog \#135302, Synaptic System), mouse antivesicular GABA transporter (VGAT; 1:1000; catalog \#131011, Synaptic System), rabbit anti-Cannabinoid receptor type 1 (CB1R; 1:1000; catalog
\#258003, Synaptic System), mouse anti-Synaptotagmin 2 (1:400; catalog \#AB-23626, Developmental Studies Hybridoma Bank), rabbit anti-c-fos (1:1000; catalog \#226003 Synaptic System), guinea pig anti-VGLUT3 (1:500; catalog \#135204, Synaptic System), and rabbit anti-RFP (1:2000; 


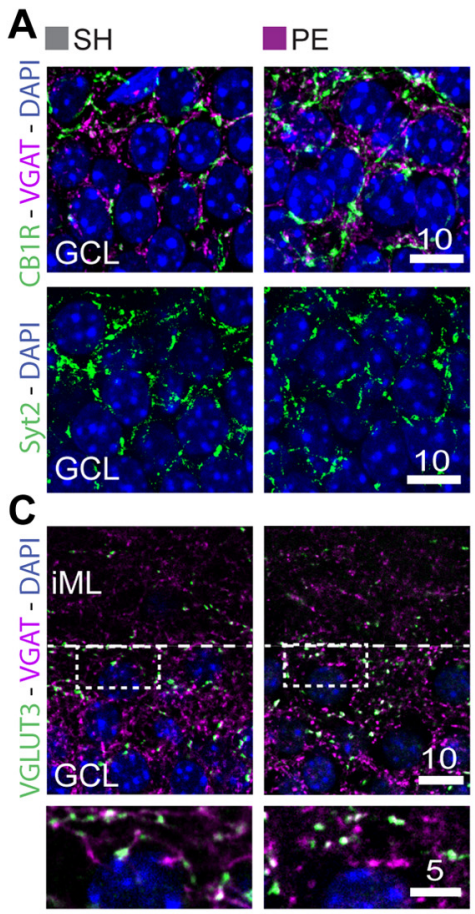

B
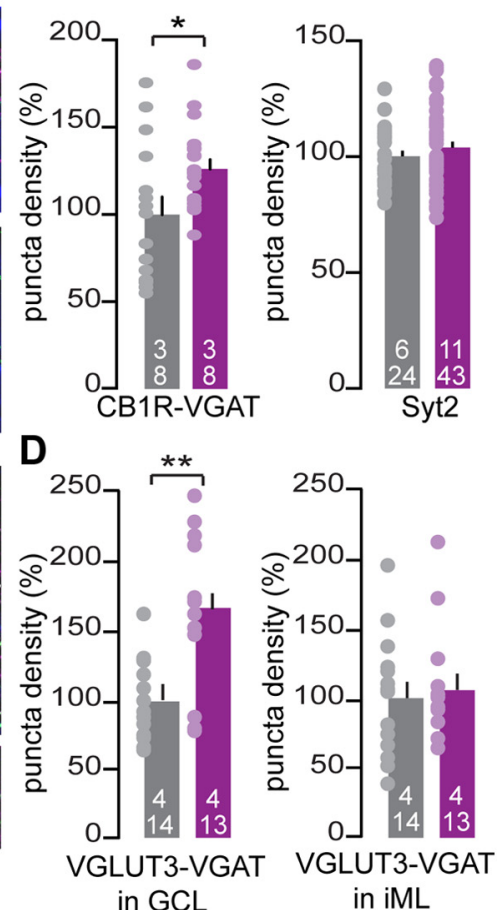

E

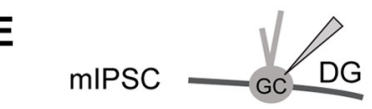

$\mathrm{SH}$

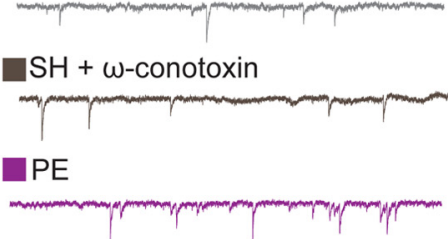

PE $+\omega$-conotoxin

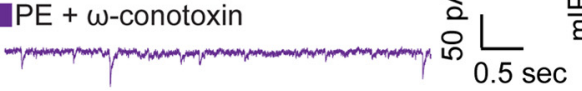

$\mathbf{F}$

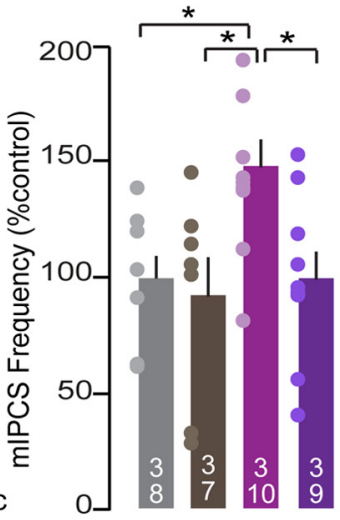

Figure 3. $\mathrm{PE}$ enhances $\mathrm{CCK}{ }^{+}$somatic synapses in the $\mathrm{DG}$. $\boldsymbol{A}$, Representative images of the $\mathrm{GC}$ layer stained with either antibodies against VGAT (magenta) and CB1R (green) or Syt2 (green) from brain sections of SH and PE mice. Scale bars in $\mu \mathrm{m}$. B, Corresponding quantification of CCK + basket cell synapses (overlap of VGAT and (B1R) and PV + synapses (Syt2) in the $\mathrm{GC}$ layer. Statistic by a two-sample $t$ test, ${ }^{*} p<0.05$. Non-normalized data are presented in Table 1. C, Representative images of the iML and the GC layer stained with antibodies against VGAT (magenta) and VGLUT3 (green) from brain sections of $\mathrm{SH}$ and PE mice. The dashed line represents boundary of $\mathrm{MLL}$ and $\mathrm{GCL}$; box with dashed line indicates the region at high magnification shown below. Scale bars in $\mu \mathrm{m}$. $\boldsymbol{D}$, Corresponding quantification of $\mathrm{CCK}+$ basket cell synapses labeled with VGAT and VGLUT3 in the iML and GC layer. Statistic by a two-sample $t$ test, ${ }^{* *} p<0.01$. Non-normalized data are presented in Table 1. $\boldsymbol{E}$, Representative mIPSC traces recorded from mouse GCS (P19-21) in the absence or presence of $1 \mu \mathrm{m}$ extracellular $\omega$-conotoxin GVIA from SH and PE mice. $\boldsymbol{F}$, Summary graphs of the average frequency. All data were normalized to SH control. Statistical comparisons were performed with a one-way ANOVA ( $\left.{ }^{*} p<0.05\right)$ followed by Tukey's honestly significant difference post hoc test. Data represent mean \pm SEM. The number of animals and the number of images or of recorded cells used are reported within each bar $(\mathrm{a} / \mathrm{n})$.

catalog \#600-401-379, Rockland). Fluorescent secondary antibodies were purchased from Invitrogen (catalog \#A32728, A11008, A11031, A31573).

Imaging and quantification. Images were collected at 8-bit depth and $1024 \times 1024$ pixel resolution and $400 \mathrm{~Hz}$ scanning speed under an inverted Leica TCS-SP8 confocal microscope. For synaptic bouton and cluster analysis, images were acquired with a $40 \times, 1.3$ oil objective and zoom factor at 3 . For c-fos density analysis, images were acquired with a $20 \times, 0.75$ oil immersion objective. All our images were acquired from at least 3-4 hemispheres per mice and at least three animals per group. Images were taken in the dorsal regions of the hippocampus. Puncta density and GFP cluster analysis were performed blind to experimental conditions using Imaris 9.5 (Bitplane). First, a three-dimensional (3D) region of interest (3D-ROI) was defined using anatomic cues. For the outer granular cell layer (GCL), the two-third outer section of the GCL was used, easily distinguishable because of the presence of larger and less compact nuclei, whereas for the inner granular cell layer (containing neural progenitor cells and not used for our analysis), nuclei are small and densely packed. For the quantifications of the somatic inhibitory synapses, the analyses were always performed in the outer GCL. To distinguish the inner molecular layer (ML) from the middle and outer molecular layer, we relied on labeled anatomic cues whenever possible. For instance, labeling of the PP with mCherry demarcates the outer ML, whereas labeling of the dense and compact commissural axon terminals with CB1R demarcates the inner molecular layer. When no labeling of such cues were available (VGLUT1 detection, Fig. 1H,I), we estimated the limit of the inner molecular layer (iML) from the border of the GCL as one fourth of the length of the entire ML (Change in VGLUT1 puncta density along the layers of the DG was also a useful visual guide to draw our 3D-ROI.). Synaptic and axon puncta were detected by the Imaris automatic spot detection algorithm using an average diameter of $0.5 \mathrm{~mm}$ and by adjusting the intensity threshold for each image. Subsequently, the number of detected spots was then divided by the volume of the 3D-ROI. For the detection of putative CCK-BC terminals, puncta were defined using the colocalization algorithm of Imaris software using CB1R and VGAT channels or VGLUT3 and VGAT. For gephyrin-GFP cluster counting, dendrite tracing was performed manually by the Filament tools in Imaris. Taking advantage of anatomic cues in combination with labeling of the PP with farnesylated tdTomato (following viral injection to target EC2 neurons), clusters were counted within distinct dendritic segments present in DG laminae (Fig. 2D). Plotted data represented numbers of puncta per $\mu \mathrm{m}$ (Fig, $2 E, F$; see Table 2). For puncta counting and analysis (Figs. 2, 3, 6, 7), the data were normalized to values obtained from control SH examined in parallel. This normalization was used to account for potential variability in synapse density across independent experiments. The values obtained from both $\mathrm{PE}$ and $\mathrm{SH}$ mice were adjusted to the mean for $\mathrm{SH}$ and reported as percentages. The non-normalized data are presented in Table 1.

Statistics. All statistical analyses were performed using IBM SPSS. All data are presented as mean \pm SEM. Data were analyzed with parametric tests, including 2-tailed two-sample $t$ test or one-way ANOVA followed by Tukey's post hoc analysis for comparisons of multiple samples. Probability distributions were compared using the KolmogorovSmirnov test. Sample sizes were not predetermined but are similar to those reported by previous publications in the field (Pieraut et al., 2014; Hartzell et al., 2018; Soh et al., 2018). The digital numbers present within the histogram bars of all figures represent the number of animals per condition (top) and the number of biological replicates (bottom). Statistical details of experiments can be found in the figure legends; $p$ values $<0.05$ were considered statistically significant. 
Table 1. Synaptic puncta density in SH and PE mice

\begin{tabular}{|c|c|c|c|c|c|c|c|c|}
\hline & Layer & & Puncta density $\left(/ \mu \mathrm{m}^{3}\right)^{a}$ & $t^{b}$ & $p^{b}$ & Puncta density $(\% \mathrm{SH})^{a}$ & $t^{c}$ & $p^{c}$ \\
\hline \multirow[t]{8}{*}{ VGAT } & \multirow[t]{2}{*}{ ML } & SH & $0.287 \pm 0.013$ & 2.405 & \multirow[t]{2}{*}{$0.019 *$} & \multirow[t]{2}{*}{$100 \pm 3.89$} & \multirow[t]{2}{*}{2.940} & \multirow[t]{2}{*}{$0.0046 * *$} \\
\hline & & $\mathrm{PE}$ & $0.332 \pm 0.012$ & $115.61 \pm 3.32$ & & & & \\
\hline & \multirow[t]{2}{*}{$\mathrm{iML}$} & SH & $0.168 \pm 0.014$ & 0.608 & \multirow[t]{2}{*}{0.548} & \multirow[t]{2}{*}{$100 \pm 8.34$} & \multirow[t]{2}{*}{0.608} & \multirow[t]{2}{*}{0.55} \\
\hline & & PE & $0.179 \pm 0.012$ & $106.86 \pm 7.08$ & & & & \\
\hline & \multirow[t]{2}{*}{$\mathrm{GCL}$} & SH & $0.100 \pm 0.005$ & 3.401 & \multirow[t]{2}{*}{$0.001 * *$} & \multirow[t]{2}{*}{$100 \pm 4.42$} & \multirow[t]{2}{*}{3.746} & \multirow[t]{2}{*}{$0.0004 * * *$} \\
\hline & & PE & $0.128 \pm 0.006$ & $129.15 \pm 6.41$ & & & & \\
\hline & \multirow[t]{2}{*}{ Hilus } & SH & $0.066 \pm 0.003$ & 0.635 & \multirow[t]{2}{*}{0.532} & \multirow[t]{2}{*}{$100 \pm 4.03$} & \multirow[t]{2}{*}{0.635} & \multirow[t]{2}{*}{0.53} \\
\hline & & PE & $0.063 \pm 0.003$ & $94.90 \pm 4.84$ & & & & \\
\hline \multirow[t]{2}{*}{ CB1R-VGAT } & \multirow[t]{2}{*}{$\mathrm{GCL}$} & SH & $0.0070 \pm 0.0007$ & 2.439 & \multirow[t]{2}{*}{$0.021 *$} & \multirow[t]{2}{*}{$100 \pm 10.02$} & \multirow[t]{2}{*}{2.439} & \multirow[t]{2}{*}{$0.021 *$} \\
\hline & & PE & $0.0088 \pm 0.0003$ & $126.10 \pm 5.31$ & & & & \\
\hline \multirow[t]{2}{*}{ Syt2 } & \multirow[t]{2}{*}{$\mathrm{GCL}$} & SH & $0.0325 \pm 0.0027$ & 0.175 & \multirow[t]{2}{*}{0.862} & \multirow[t]{2}{*}{$100 \pm 2.50$} & \multirow[t]{2}{*}{0.986} & \multirow[t]{2}{*}{0.33} \\
\hline & & PE & $0.0331 \pm 0.0023$ & $103.86 \pm 2.57$ & & & & \\
\hline \multirow[t]{4}{*}{ VGLUT3-VGAT } & \multirow[t]{3}{*}{ iML } & SH & $0.0126 \pm 0.0015$ & 0.381 & \multirow[t]{3}{*}{0.706} & $100 \pm 11.73$ & 0.381 & 0.71 \\
\hline & & PE & $0.0082 \pm 0.0009$ & $165.86 \pm 15.96$ & & & & \\
\hline & & PE & $0.0134 \pm 0.0014$ & $106.34 \pm 11.75$ & & & & \\
\hline & $\mathrm{GCL}$ & SH & $0.0050 \pm 0.0004$ & 3.702 & $0.002 * *$ & $100 \pm 7.85$ & 3.702 & $0.002 * *$ \\
\hline
\end{tabular}

The density of the synaptic puncta in the different layers of the DG were quantified in $\mathrm{SH}$ and PE mice. Puncta densities are reported as number of puncta per cubic micrometer (/ $\left.\mu \mathrm{m}^{3}\right)$ or as percentage of control (\%SH). ${ }^{a}$ All data are represented as mean \pm SEM

${ }^{b}$ Statistical comparisons for each layer were performed for the original data of puncta density $\left(/ \mu \mathrm{m}^{3}\right)$, with a two-sample $t$ test.

'Statistical comparisons for each layer were performed for the normalized data of puncta density (\%SH), with a two-sample $t$ test. Asterisks indicate significant difference between groups $\left(* p<0.05,{ }^{* *} p<0.01{ }^{* * * *} p<\right.$ 0.001).

Table 2. Density of the gephyrin-GFP clusters along the somatodendritic axis of the GCs in SH and PE mice

\begin{tabular}{lllll}
\hline & & Puncta density $\left(/ \mu \mathrm{m}^{3}\right)^{a}$ & $t^{b}$ & $p^{b}$ \\
\hline DD & SH & $0.281 \pm 0.014$ & 0.304 & 0.762 \\
& PE & $0.275 \pm 0.012$ & & \\
MD & SH & $0.247 \pm 0.015$ & 0.809 & 0.422 \\
& PE & $0.232 \pm 0.011$ & & \\
PD & SH & $0.338 \pm 0.035$ & 2.107 & $0.039 *$ \\
& PE & $0.433 \pm 0.029$ & & \\
\multirow{2}{*}{ AIS } & SH & $0.393 \pm 0.031$ & 0.07 & 0.945 \\
\multirow{2}{*}{ Soma $^{\#}$} & PE & $0.388 \pm 0.053$ & & \\
& SH & $34.50 \pm 1.677^{\#}$ & 3.108 & $0.0029 * *$ \\
& PE & $44.42 \pm 2.716^{\#}$ & & \\
\hline
\end{tabular}

Density of tde gephyrin-GFP clusters are reported as number of cluster per micrometer along the DDs in the ML, medial dendrites (MDs) in the inner ML, the proximal dendrites (PDs) in the GCL and the axon initial segment (AIS) in the hilus. For the soma, data are reported as number of gephyrin-GFP clusters per soma $\left({ }^{\#}\right)$.

${ }^{a}$ All data are represented as mean \pm SEM.

${ }^{b}$ Statistical comparisons for each segment were performed for original data of puncta density $\left(/ \mu \mathrm{m}^{3}\right)$, with a two-sample $t$ test. Asterisks indicate significant difference between groups $\left({ }^{*} p<0.05,{ }^{* *} p<0.01\right)$.

\section{Results}

\section{PE induces an increase in inhibitory and excitatory drive in the DG}

To investigate how early postnatal experience affects the synaptic network in the hippocampus, mice were raised in a standard laboratory cage or in a large cage containing toys, a hamster wheel, and diverse objects that were changed every other day (Fig. 1A). In these EE cages, pups were raised for $21 \mathrm{~d}$ with their mothers and an additional female to increase nurturing. Miniature inhibitory and excitatory postsynaptic currents (mIPSC and mEPSC) were then recorded from the excitatory GCs in the DG using acute brain slices (Fig. 1B,E). We found a significant increase in the frequency of mEPSCs (SH: $1.82 \pm 0.21 \mathrm{~Hz} ; \mathrm{PE}: 2.40 \pm$ $0.25 \mathrm{~Hz} ; t_{(23)}=2.4, p=0.025$; Fig. $\left.1 D\right)$, with no significant changes in mEPSC amplitudes (SH: $7.299 \pm 0.446 \mathrm{pA}$; PE: $6.74 \pm 0.51 \mathrm{pA} ; t_{(23)}=0.428, p=0.67$; Fig. $1 C$ ). Similarly, recording of the mIPSC showed a significant enhancement in the frequency of these events (SH: $1.19 \pm 0.12 \mathrm{~Hz}$; PE: $1.82 \pm 0.17 \mathrm{~Hz}$; $t_{(34)}=3.034, p=0.005$; Fig. $1 G$ ) but no change in the amplitude of $\operatorname{mIPSC}$ (SH: $21.10 \pm 1.58 \mathrm{pA}$; PE: $18.11 \pm 3.25 \mathrm{pA} ; t_{(34)}=$
0.904, $p=0.37$; Fig. $1 F$ ). These results suggest that either an increase of the number of excitatory and inhibitory inputs on GC or a change in the release probability of the existing inputs or both. To establish whether the increase in $\mathrm{mEPSC}$ frequency correlates with an increase of excitatory synapses in the ML of the DG, we performed immunohistochemistry using an antibody targeting the excitatory presynaptic protein VGLUT1, a marker of choice for glutamatergic nerve terminals and glutamatergic synapses (Micheva et al., 2010). Labeling and imaging of brain sections obtained from animals raised in either the $\mathrm{SH}$ or the $\mathrm{PE}$ condition demonstrates an increase in the density of VGLUT1 puncta in the ML of mice raised in EE (SH: $100 \pm 7.74 \%$; PE: $146.12 \pm 5.68 \% ; t_{(62)}=4.869, p<0.0001$; Fig. $\left.1 H, I\right)$. This increase in VGLUT1 puncta density reflects an increase of excitatory synapses formed onto GC dendrites and is in accordance with previous studies (Hosseiny et al., 2015). The observed increase of mIPSC frequency in our experiment suggests that the circuit is adding inhibitory synapses to maintain a proper excitatory-inhibitory balance in the DG. Although an increase in mIPSC frequency has previously been observed in the DG of mice raised in an EE (He et al., 2010; Liu et al., 2012), the cellular origin of the enhanced inhibitory synaptic drive is unclear. We therefore designed a series of experiments to test whether specific inhibitory cell types are more sensitive to experience-dependent plasticity in the DG.

\section{PE increases GC perisomatic inhibition}

The dentate gyrus is populated by a diverse population of inhibitory interneurons with distinct morphologic and molecular characteristics. These neurons innervate their axons to the specific laminae within the DG and provide unique inhibitory modalities to GCs. For instance, the soma of somatostatin-expressing cells are present in the hilus and contact the apical dendrites of GC in the ML, providing weak and slow dendritic inhibition (Savanthrapadian et al., 2014; Yuan et al., 2017). On the other hand, perisomatic inhibition is controlled by both the CCK+ and PV + basket cells that are present in the GCL, and in accordance with their propitious subcellular targeting, these cell types exert strong temporal control on GC action potential generation 


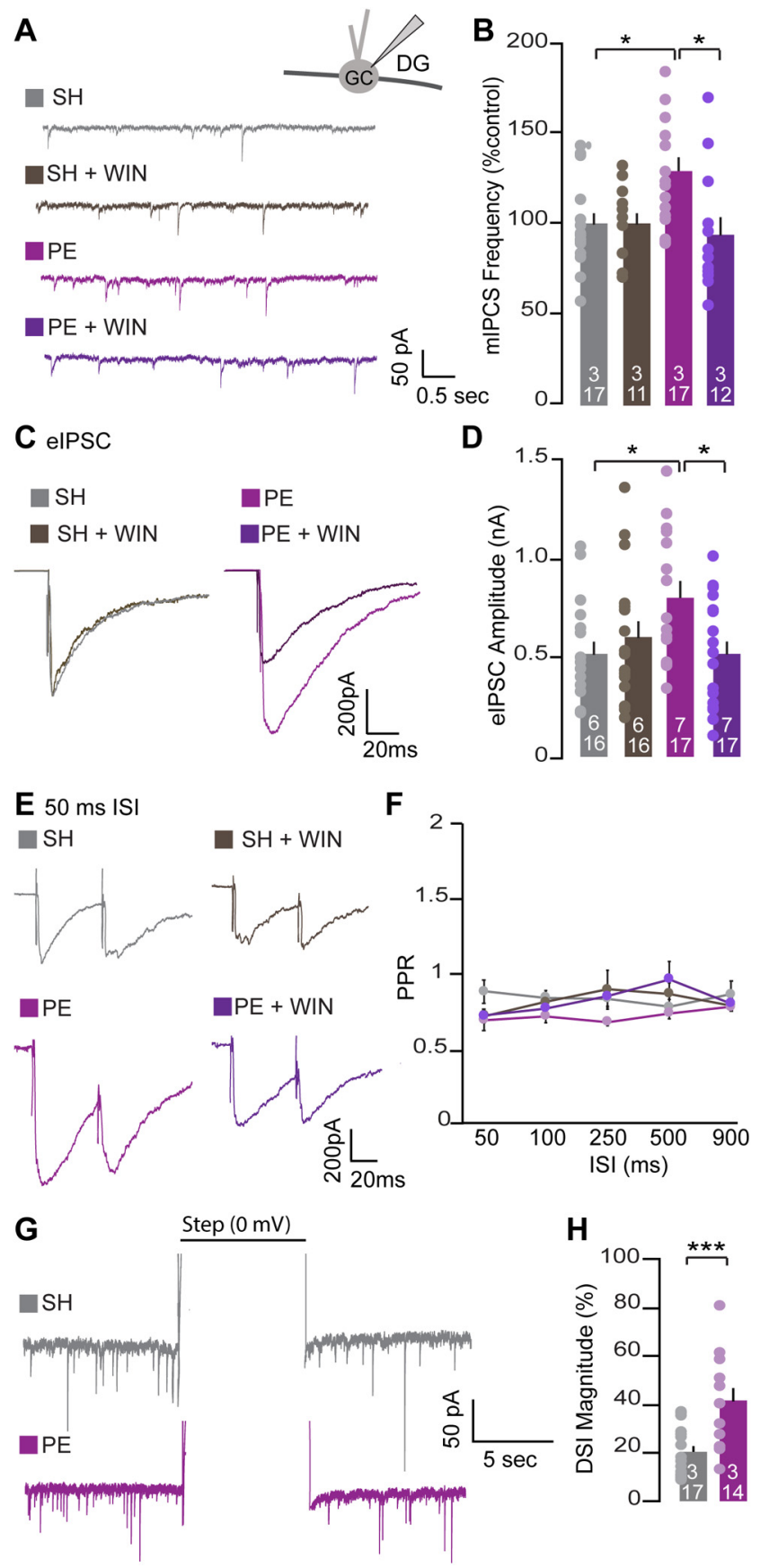

Figure 4. EE increases $\mathrm{GABA}$ release and magnitude of DSI by $\mathrm{CCK}^{+}$inputs. All whole-cell recordings were performed from $\mathrm{GCS}$ of $\mathrm{SH}$ and PE mice (P19-21). $A$, Representative mIPSC traces recorded in the absence or presence of $5 \mu \mathrm{m}$ extracellular WIN $55212-2$ (WIN). $\boldsymbol{B}$, Summary graphs of the average frequency. All data were normalized to SH control. Statistical comparisons were performed with a one-way ANOVA ( $\left.{ }^{*} p<0.05\right)$ followed by Tukey's honestly significant difference post hoc test. $\boldsymbol{C}$, Representative example of traces of the evoked IPSC recorded before and after WIN. D, Summary graphs of the average amplitudes. Statistical comparisons were performed with a one-way ANOVA $\left({ }^{*} p<0.05\right)$ followed by Tukey's honestly significant difference post hoc test. $\boldsymbol{E}$. Example of paired-pulse eIPSC traces recorded with a $50 \mathrm{~ms}$ interstimulus interval (ISI) before and after WIN. $\boldsymbol{F}$, Summary graph of the averaged PPRs for ISls of $50 \mathrm{~ms}, 100 \mathrm{~ms}, 250 \mathrm{~ms}, 500 \mathrm{~ms}$, and $900 \mathrm{~ms}$. Statistical comparisons were performed with a one-way ANOVA. Data are presented in Table 3. G, Representative spontaneous IPSC traces recorded before and after depolarizationinduced DSI (+70 mV, truncated). $\boldsymbol{H}$, DSI magnitude expressed as percentage of the reduction in charge transfer after DSI induction in all four groups. Statistical comparisons were performed with a two-sample $t$ test $\left({ }^{* * *} p<0.001\right)$. Data represent mean \pm SEM. The number of animals and recorded cells used are reported within each bar $(\mathrm{a} / \mathrm{n})$.
Table 3. Pair-pulse ratio of the eIPSC at different interstimulus interval

\begin{tabular}{|c|c|c|c|c|c|c|}
\hline \multirow[b]{2}{*}{ ISIs (ms) } & \multicolumn{2}{|l|}{$\mathrm{SH}^{a}$} & \multicolumn{2}{|l|}{$\mathrm{PE}^{a}$} & \multirow[b]{2}{*}{$F^{b}$} & \multirow[b]{2}{*}{$p^{b}$} \\
\hline & Before WIN & After WIN & Before WIN & After WIN & & \\
\hline 900 & $0.87 \pm 0.089$ & $0.79 \pm 0.038$ & $0.78 \pm 0.029$ & $0.81 \pm 0.037$ & 0.489 & 0.691 \\
\hline 500 & $0.78 \pm 0.049$ & $0.87 \pm 0.072$ & $0.74 \pm 0.040$ & $0.97 \pm 0.012$ & 1.771 & 0.162 \\
\hline 250 & $0.84 \pm 0.056$ & $0.90 \pm 0.131$ & $0.68 \pm 0.023$ & $0.85 \pm 0.063$ & 1.486 & 0.227 \\
\hline 100 & $0.85 \pm 0.046$ & $0.82 \pm 0.037$ & $0.72 \pm 0.044$ & $0.77 \pm 0.031$ & 1.789 & 0.159 \\
\hline 50 & $0.89 \pm 0.077$ & $0.72 \pm 0.045$ & $0.70 \pm 0.067$ & $0.73 \pm 0.043$ & 2.110 & 0.108 \\
\hline
\end{tabular}

Evoked inhibitory postsynaptic currents recorded from the granular cells were evoked at different interstimulus intervals before and after bath application of WIN. ISI, Interstimulus interval. The corresponding pairpulse ratios are reported for SH and PE mice.

${ }^{a}$ All data are represented as mean \pm SEM.

${ }^{b}$ Statistical comparisons were performed with a one-way ANOVA.

(Hefft and Jonas, 2005; Bartos and Elgueta, 2012; Fig. 2A). Using an antibody targeting vesicular GABA transporter (VGAT) present at all inhibitory presynaptic terminals, we were able to quantify the density of inhibitory synapses present in the different layers of the DG (Fig. 2A,B). We measured VGAT puncta density in the ML, iML, GCL, and hilus using 3D puncta quantification. We found a specific increase in VGAT puncta density in the ML and GCL (ML, SH: $100 \pm 3.89 \%$, PE: $115.61 \pm 3.32 \%, t_{(62)}=2.94, p=0.0046 ;$ GCL, SH: $100 \pm$ $4.42 \%$, PE: $\left.129.15 \pm 6.41 \%, t_{(63)}=3.746, p=0.00,039\right)$, but no significant change in the hilus or in the iML (hilus, SH: $100 \pm 4.03 \%$, PE: $94.90 \pm 4.84 \%, t_{(22)}=0.635, p=0.53$; iML, PE: $106.86 \pm 7.09 \%$, SH: $100 \pm 8.34 \%, t_{(28)}=0.608, p=0.55$; Fig. $2 C$; Table 1). This result suggests that the increased inhibitory drive on the GCs observed with MIPSC recording is, at least in part, because of the structural plasticity involving an increase of dendritic and somatic inhibition onto GCs. To confirm that an increase in VGAT puncta density reflects the addition of inhibitory synaptic inputs onto the GCs, we used a viral approach to express the inhibitory postsynaptic protein, gephyrin fused to GFP in GC. Viral injection of AAVDJhSyn-GFP-Gephyrin in combination with AAVDJ-Ef1 $\alpha$ tdTomato-farnesylated (AAV-EF1 $\alpha$-tdT-F) were done at P1, and the brain was harvested after mice were raised in $\mathrm{SH}$ or EE for 3 weeks. The labeling of the perforant path with tdT-F allowed us to distinguish distinct segments of the GC dendrites across the different laminae and to quantify GephyrinGFP clusters on these segments along the somatodendritic axis of the GCs (Fig. 2D). In accordance with an increase in VGAT puncta density in the GCL, we found a significant increase of Gephyrin-GFP clusters present on GC somas and proximal dendrites (PD; soma, SH: $34.50 \pm 1.68, \mathrm{PE}: 44.42 \pm$ $2.72, t_{(60)}=3.108, p=0.0029 ; \mathrm{PD}, \mathrm{SH}: 0.34 \pm 0.04, \mathrm{PE}:$ $0.43 \pm 0.03, t_{(60)}=2.107, p=0.039$; Fig. $2 E, F$; Table 2). The number of Gephyrin-GFP puncta on the GC axon initial segments (AIS) was not affected by EE (SH: $0.39 \pm 0.03$; PE: $0.39 \pm 0.05 ; t_{(47)}=0.07, p=0.945$ ), which suggests that synaptic inputs from axo-axonic inhibitory cells such as $\mathrm{PV}+$ chandelier cells are not altered by EE. Surprisingly, despite a mild but significant increase of VGAT puncta density in the ML following EE (Fig. 2C), no increase of Gephyrin-GFP clusters were found on the dendrites of the GCs in PE mice [distal dendrites (DD), SH: $0.28 \pm 0.01$, PE: $0.28 \pm 0.01, t_{(60)}=0.304$, $p=0.762$; MD, SH: $0.25 \pm 0.02$, PE: $0.23 \pm 0.01, \mathrm{t}_{(60)}=0.809$, $p=0.422$; Fig. 2E; Table 2]. Altogether, these results suggest that enhanced spontaneous inhibitory activity on GCs is because of an increase in somatic inhibition on GCs and demonstrate that experience-dependent synaptic plasticity is restricted to specific inhibitory cell types that target GC soma. 


\section{$\mathrm{CCK}+$ but not $\mathrm{PV}+$ somatic inputs are increased by $\mathrm{PE}$}

Despite shared anatomic similarities between $\mathrm{CCK}+$ and PV + basket cells, they differ in the way they gate GC activity (Hefft and Jonas, 2005). This is due in part to the differences in their connectivity patterns, intrinsic excitability, and differential expression of receptors and channels that modulate their activity. For instance, Synaptotagmin 2 is enriched in $\mathrm{PV}+$ basket cell terminals, which is critical to sustain high-frequency GABA release (Sommeijer and Levelt, 2012; Chen et al., 2017). CCK-BCs, on the other hand, express $\mathrm{CB} 1 \mathrm{R}$ at their synaptic terminals and are therefore sensitive to cannabinoid retrograde signaling (Katona et al., 1999). Surprisingly, the CCK + inhibitory terminals also contain vesicular glutamate transporter 3 (VGLUT3) supporting an unusual presynaptic glutamate/GABA corelease (Somogyi et al., 2004; del Pino et al., 2017; Fasano et al., 2017; Pelkey et al., 2020). Considering their critical roles in information processing, we questioned how each cell type contributes to the increased somatic inhibition caused by EE. To this end, we first labeled the somatic innervation of the two BC axonal boutons using a combination of antibodies against their respective synaptic markers; antibody against Syt2 were used to label PV + terminals, and double staining using antibodies against CB1R/ VGAT and VGLUT3/VGAT were used for $\mathrm{CCK}+$ terminals (Fig. $3 A, C$ ). Brain sections were obtained from 3 -week-old mice raised in $\mathrm{SH}$ or EE. Then, the puncta density was quantified. We found that although CB1R/ VGAT puncta density was increased by $26 \%$ and VGLUT3/VGAT by $65 \%$, no change in Syt2 puncta density was found (CB1R/ VGAT, SH: $100 \pm 10.02 \%$, PE: $126.10 \pm 5.31 \%, t_{(32)}=2.439$, $p=0.021$; Syt $2, \mathrm{SH}: 100 \pm 2.5 \%, \mathrm{PE}: 103.86 \pm 2.57 \%, t_{(65)}=$ $0.986, p=0.328$; VGLUT3/VGAT, SH: $100 \pm 7.86 \%$, PE: $165.86 \pm 15.96 \%, t_{(17.56)}=3.702, p=0.002$; Fig. $3 B$; Table 1$)$. The result demonstrates that the density of CCK + synapses on GC soma is increased by EE, whereas PV+ inputs are unchanged. Interestingly, the observed increased of VGLUT3/VGAT overlap did not take place in the inner ML despite the fact that CCK+ axon span both the GCL and the ML (Hefft and Jonas, 2005; Taniguchi et al., 2011; Savanthrapadian et al., 2014; Yu et al., 2016; SH, $100 \pm 11.73 \%$; PE, $106.34 \pm 11.75 \% ; t_{(25)}=0.381, p=0.706$; Fig. 3D; Table 1). Altogether our synaptic labeling quantifications demonstrate that $\mathrm{PE}$ induces an increase of inhibitory synapses from CCK-BCs, specifically in the GCL. Next, we asked whether the increase in mIPSC frequency observed in the PE group (Fig. $1 G$ ) could be reversed by specifically blocking spontaneous release at inhibitory CCK + synapses. For this purpose we used $\omega$-conotoxin GVIa $(\omega$-Ctx), an N-type voltage-gated calcium channel (VGCC) blocker, specifically blocking mIPSC from CCK+ terminals that express CB1R (Goswami et al., 2012). We observed that the increase in mIPSC frequency in PE condition was almost completely blocked by bath application of $\omega$-Ctx $(1 \mu \mathrm{M} ; \mathrm{SH}$ :
$100 \pm 9.87 \%$, SH with blocker: $92.31 \pm 16.88 \%$; PE: $147.88 \pm$ $11.76 \%$, PE with blocker: $99.35 \pm 12.11 \% ; F_{(3,30)}=4.495, p=0.01$; Fig. $3 C, D)$. These data strongly suggest that the increased somatic inhibition induced by PE is because of the selective addition of $\mathrm{CCK}+$ inhibitory somatic inputs onto GCs.

\section{Experience-dependent remodeling of CCK + inputs modulate CB1R-mediated regulation of inhibition}

$\mathrm{CCK}+$ cells provide a slow and asynchronous inhibition strongly controlled by neuromodulators (Hefft and Jonas, 2005; Földy et al., 2007; Lee and Soltesz, 2011; Bartos and Elgueta, 2012). During repetitive activation of the GC, local retrograde $\mathrm{CB} 1$ signaling will activate CB1R present at $\mathrm{CCK}+$ terminals and block the release of GABA (Wilson and Nicoll, 2001; Isokawa and Alger, 2005). Disinhibition from CCK + cells activated by this signaling is termed DSI. To provide more evidence that the $\mathrm{CCK}+$ terminal is regulated by EE and to assess how this plasticity affects CB1R-mediated regulation of inhibition, we performed a series of recordings using the CB1 receptor agonist WIN (previously shown to block the release of GABA at CCK+ terminals (Katona et al., 1999; Goswami et al., 2012). Similar to $\omega$-Ctx, bath application of $5 \mu \mathrm{M}$ WIN during $\mathrm{mIPSC}$ recording reversed 


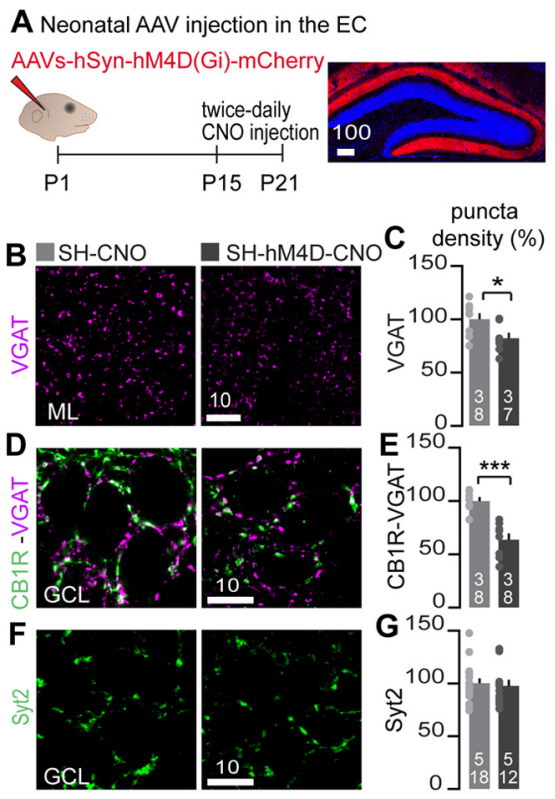

Figure 6. Experience-dependent remodeling of $\mathrm{CCK}+$ basket cell inputs is controlled by EC2 neuron activity. $A$, Left, Experimental paradigm for chemogenetic inhibition of excitatory afferents from EC2 in the DG circuit. Right, Representative image of the perforant path fibers in the DG (afferents from the EC2) labeled with mCherry (red) following neonatal injection of AAV-hSyn-hM4D(Gi)-mCherry in the EC. $\boldsymbol{B}, \boldsymbol{D}, \boldsymbol{F}$, Representative images of the GCL and ML stained with antibodies against either, VGAT (magenta; $\boldsymbol{B}, \boldsymbol{D}$ ), CB1R (green; $\boldsymbol{D}$ ), or Syt2 (green; $\boldsymbol{F}$ ) from brain sections of $\mathrm{SH}$ mice injected or not with hM4Di-expressing virus and treated with CNO (SH-hM4D-CNO and SH-CNO, respectively). C, E, G, Corresponding quantification of GABAergic terminals (VGAT; $\boldsymbol{C}$ ) in the ML, CCK+ synapses (VGAT/CB1R; $\boldsymbol{E}$ ), and $\mathrm{PV}+$ synapses (Syt2; G) in the GCL. All data were normalized to SH-CNO control. Statistical comparisons were performed with a two-sample $t$ test $\left({ }^{*} p<0.05\right.$ and $\left.{ }^{* * *} p<0.001\right)$. Graph bars represent mean \pm SEM. The number of animals and images used are reported within each bar $(\mathrm{a} / \mathrm{n})$. All scale bars are in $\mu \mathrm{m}$.

the increase in mIPSC frequency observed in PE mice but had no effect on mIPSC amplitude (SH: $100 \pm 5.76 \%$, SH with WIN: $99.96 \pm 6.34 \%$; PE: $129.65 \pm 8.43 \%$, PE with WIN: $94.52 \pm$ $9.85 \% ; F_{(3,53)}=4.630, p=0.006$; Fig. $\left.4 A, B\right)$. We then performed the recording of eIPSC in GCs by placing the stimulating electrode in the outer GCL to favor the response from CCK-BCs. The amplitude of eIPSC recorded in this condition was increased by $56 \%$ in $\mathrm{PE}$ mice compared with $\mathrm{SH}$ mice, and this increase was abolished by bath application of WIN. Interestingly, the drug had no effect on the amplitude of eIPSC recorded in $\mathrm{SH}$ mice (SH: $517.53 \pm 66.58 \mathrm{pA}$, SH with WIN: 604.82 $\pm 84.77 \mathrm{pA}$; PE: $808.01 \pm 83.02 \mathrm{pA}, \mathrm{PE}$ with WIN: $518.24 \pm 67.51 \mathrm{pA} ; F_{(3,62)}$ $=3.312, p=0.026$; Fig. $4 C, D)$. Moreover, the lower eIPSC amplitude in $\mathrm{SH}$ mice is unlikely because of change in GABA release probability because the pair-pulse ratio of the eIPSC recorded on GCs at different intervals did not differ in SH and PE mice and were not affected by bath application of WIN (Fig. 4E,F; Table $3)$. Therefore, the effect of CB1R agonist WIN on mIPSC frequency and eIPSC amplitude further support the notion that the observed increase inhibition activated by $\mathrm{EE}$ is because of the selective addition of CCK-BC synapses. It also favors a model in which mice raised in an EE have enhanced CB1R-mediated regulation of inhibition. To confirm this assumption, we then monitored DSI in the DG of SH and PE mice. Spontaneous IPSCs were recorded at a holding potential of $-70 \mathrm{mV}$ in GCs, and DSI was induced by a $1 \mathrm{~Hz}$ train with 8 depolarizations to $0 \mathrm{mV}$. Spontaneous IPSCs in the SH group were suppressed by $~ 20 \%$ after depolarization (DSI magnitude), whereas the DSI magnitude was increased twofold in PE mice (DSI magnitude, SH: $19.65 \pm 2.49 \%$; PE: $41.49 \pm 5.16 \%$; $t_{(29)}=4.034, p=0.00,037$; Fig. $4 G, H)$. Together, these results demonstrate that raising mice in an $\mathrm{EE}$ increases CB1R-mediated inhibition in the DG through the addition of CCK-BC synapses onto principal GC.

\section{GC innervation by CCK-BCs is controlled by the activity of the perforant path}

In the DG, the fibers of the PP originate from the EC2 longrange projection neurons. Their axons carry multimodal sensory information and form the major excitatory inputs in the circuit (Witter and Moser, 2006; Knierim et al., 2014). Previous work has demonstrated that the activity of EC2 afferents has an instructional role in DG maturation (Pieraut et al., 2014; Donato et al., 2017). We therefore reasoned that activity from these afferents could also regulate the plasticity of CCK + interneurons. To test this hypothesis, we manipulated activity of EC2 neurons using viral-mediated expression of the designer receptors exclusively activated by designer drugs (DREADD) receptor hM4Di. Injection of AAV-mCherry-hM4Di in the EC in neonate led to the expression of the DREADD receptor in $\sim 23 \%$ of the cells in the layer 2 of the EC (Fig. 5B). First, we tested whether expression of hM4Di and its activation with $\mathrm{CNO}$ were sufficient to suppress the experience-dependent expression of an immediate early gene, c-fos, in the DG. Naive mice, 3 weeks old, previously injected with AAV-hSyn-hM4Di-mCherry in the EC at P1, were killed $90 \mathrm{~min}$ after being placed in a novel environment cage (Fig. 5A). The quantification of c-fos + cell density in the GCL, assessed using immunostaining, demonstrated that $\mathrm{CNO}$ injections repressed the experience-dependent expression of cfos in the GCL from the mice expressing hM4Di (HC: $100 \pm$ 8.76\%; NE-hM4D-NS: $195.41 \pm 14.26 \%$; NE-hM4D-CNO: $92.75 \pm$ $14.15 \% ; F_{(2,44)}=21.003, p<0.0001$; Fig. $\left.5 C\right)$. Having demonstrated that our approach enabled us to manipulate the activity of the EC projection neurons, we then chronically inhibited these EC2 afferents in naive animals raised in $\mathrm{SH}$ condition with twice daily intraperitoneal injections of CNO from P15 to P21 (Fig. 6A). We then stained brain sections with the inhibitory synaptic markers to visualize $\mathrm{CCK}+$ and $\mathrm{PV}+$ inhibitory synapses, respectively (VGAT and CB1R in one hand or Syt2 alone; Fig. 6D,F). Quantification demonstrates that chronic inhibition of the PP led to a reduction of somatic CCK+ inhibitory synapses on the GCs (SH control: $100 \pm 7.10 \%$, SH silenced: $59.678 \pm 5.39 \%$; $\mathrm{t}_{(14)}=4.522, p=0.0005$; Fig. $6 E$ ). No change in Syt 2 puncta density in the GCL was found in the same experimental condition (SH-control: $100 \pm 5.760 \%$, SH-silenced: $97.370 \pm 5.190 \%$; $t_{(28)}=$ $0.319, p=0.752$; Fig. $6 G$ ). Thus, the activity of EC2 afferents during the third week of postnatal development is critical for the maturation of inhibitory synapses formed by CCK + basket cells but not the ones formed by PV+ cells. We also assessed the density of VGAT puncta in the ML and found that the EC2 manipulation induces a reduction of the inhibitory synaptic marker in this laminae (SH control: $100 \pm 5.61 \%$, SH silenced: $81.94 \pm 5.23 \% ; t_{(13)}=2.332, p=0.036$; Fig. $\left.6 B, C\right)$. In light of these findings, we reasoned that the activity of EC2 afferents could be the driving signal regulating inhibitory plasticity in the opposite direction as observed in mice raised in an EE (i.e., addition of CCK+ synapses; Fig. 3). We therefore tested whether hM4Didependent inhibition of the EC2 projections would prevent the increase of CCK + somatic synapses observed in the PE group. In accordance with our previous experiments, $\mathrm{PE}$ induced an increase of VGAT/CB1R puncta overlap in the GCL, but this increase did not occur when the EC2 afferents were chronically . 
inhibited with the hM4Di chemogenetic approach. Importantly, the density of VGAT/ CB1R measured in PE mice not expressing hM4Di but injected with $\mathrm{CNO}$ was similar to that of control PE mice (PE-hM4D-CNO: $102.76 \pm 6.67 \%$; PE-hM4D-NS: $144.90 \pm 7.69 \%$; SH-hM4D-NS: $100 \pm 7.56 \%$; PE-CNO: $136.47 \pm$ $4.85 \%$; $p=0.0026$ for PE-hM4D-CNO and PEhM4D-NS; $p<0.0001$ for SH-hM4D-NS and PE-hM4D-NS; $F_{(3,69)}=10.313, p<0.0001$; Fig. $7 A, D)$. Finally, we measured the density of VGAT and VGLUT1 puncta in the ML to assess the effect of the silencing of the EC2 afferents on the density of excitatory and inhibitory synapses in the DG laminae where GC dendrites ramify (Fig. 7B,C). We confirmed our previous observation that raising mice in an EE leads to an increase of VGAT puncta density in the ML (Figs. 2E, 7C). However, although the silencing of the EC2 inputs in SH mice induced a reduction of the density of VGAT puncta in the ML (Fig. 6C), we did not find a statistically significant reduction in the density of VGAT puncta following the same manipulation of the inputs in PE mice (PE-hM4DCNO: $114.35 \pm 8.68 \%$; PE-hM4D-NS: $138.32 \pm$ 7.18\%; SH-hM4D-NS: $100 \pm 5.34 \%$; PE-CNO: $145.35 \pm 7.46 \% ; p<0.0001$ for SH-hM4D-NS and PE-hM4D-NS; $F_{(3,70)}=10.641, p<0.0001$; Fig. $7 E$ ). On the other hand, the increase density of VGLUT1 puncta density, observed in the mice raised in EE, was significantly reduced following the silencing of the EC2 inputs with hM4Di (PE-hM4D-CNO: $100.06 \pm 2.59 \%$; PEhM4D-NS: $142.52 \pm 3.00 \%$; SH-hM4D-NS: $100 \pm 3.34 \%$; PE-CNO: $140.33 \pm 4.65 \%$; $p<$ 0.0001 for PE-hM4D-CNO and PE-hM4DNS; $p<0.0001$ for SH-hM4D-NS and PEhM4D-NS; $F_{(3,46)}=43.052, p<0.0001$; Fig. $7 F)$. Together, these results demonstrate that activity of EC2 afferents is critical for the plasticity of inhibitory and excitatory synapses in the DG. This circuit plasticity appears to particularly affect CCK-BC terminals but not PV-BC.

\section{Discussion}

The preweaning enrichment paradigm used in this study enables us to investigate how enhanced experiences can affect the maturation of the synaptic network during postnatal development. Consistent with previous work, we found that this housing paradigm increases excitatory and inhibitory drive in the DG (Fig. 1; Liu et al., 2012; Hosseiny et al., 2015). These findings raise the following critical question: What is the cellular origin of this plasticity? In this study, we characterized a new form of plasticity that affects the formation of CCK+ inputs onto the soma of GC in the DG. Using a combination of enrichment housing and chemogenetic approaches, we demonstrate that the maturation of $\mathrm{CCK}+\mathrm{BC}$ connectivity is strongly governed by experience and requires the activation of the afferents from the EC2. By combining immunohistochemistry with cell-type specific markers and genetic labeling with gephyrin-GFP, we first demonstrate that PE leads to an increase in inhibitory synapses around the soma of the GC (Fig. 2). Immuno labeling of synaptic markers specific to $\mathrm{PV}+$ and $\mathrm{CCK}^{+}$basket cells were instrumental to distinguish the two well-characterized basket cell types in the DG and reveals that terminals from $\mathrm{CCK}+$ but not $\mathrm{PV}+$ basket cells are increased by EE (Fig. 3). This conclusion is strongly supported by the fact that the experience-dependent increase of mIPSC frequency in PE mice is blocked by the N-type VGCC blocker $\omega$-Ctx as well as CB1R agonist WIN, both of which are known to block GABA release at CCK $+/ \mathrm{CB} 1 \mathrm{R}+$ terminals (Goswami et al., 2012). Together, these experiments support the conclusion that in response to $\mathrm{PE}$, perisomatic addition of $\mathrm{CCK}+$ basket cells terminals increases the inhibitory drive onto GC.

Individual $\mathrm{CCK}+$ interneurons have axons that span both the GCL and the ML (Hefft and Jonas, 2005; Savanthrapadian et al., 2014; Yu et al., 2016). In the present study, neither VGLUT3/ VGAT puncta in the iML nor the Gephyrin-GFP clusters along the dendritic domain of the GC in the entire ML are increased in the PE mice (Figs. 2E,F, 3C,D). These data support a model in which CCK + INs plasticity is layer specific, adding synapses on 
the perisomatic region of the GCs. It is possible that the limitation of our imaging and electrophysiological approaches prevents us from finding the implication of other interneurons populations in the remodeling of the inhibitory synaptic network in PE mice. For instance, a study suggests that a subpopulation of INs, not expressing CCK, do form CB1R+ synapses in the GCL (Yu et al., 2015). However our quantification of the puncta with VGLUT3/VGAT overlaps and the blocking of mIPSC frequency with $\omega$-Ctx in PE mice strongly suggest that the increased inhibitory $\mathrm{CB} 1 \mathrm{R}+$ synapses are made by CCK-BCs (Goswami et al., 2012; Del Pino et al., 2017; Pelkey et al., 2020). The accumulation of VGAT puncta in the ML after PE suggests that dendrite targeting INs may also be affected by the experience-dependent plasticity induced by EE. However, the change in VGAT puncta density in the ML was modest and did not correlate with an increase of Gephyrin-GFP clusters in distal dendrites. Moreover, bath application of $\omega$-Ctx and WIN fully blocked the increase of mIPSC frequency observed in PE mice. It is possible that the change in VGAT puncta density in the ML reflects the addition of inhibitory synapses on inhibitory dendrites and not on excitatory GC dendrites or that axon terminals from INs are added but the maturation of the postsynaptic counterpart is delayed (Dobie and Craig, 2011; Frias et al., 2019). Nevertheless, based on the evidence presented in this study, $\mathrm{CCK}+$ basket cells play a central role in adjusting inhibition on GC through addition of somatic CB1R+ inputs.

We find it surprising that neither $\omega$-Ctx nor WIN affects the inhibitory currents recorded in SH mice (Figs. 3D, 4). This suggests that the contribution of CCK-BC synapses to basal transmission is limited in juvenile mice raised in an impoverished $\mathrm{SH}$ condition. Our result was unexpected, considering previous work showing a reduction of mIPSC frequency with these drugs (Isokawa and Alger, 2005; Goswami et al., 2012). The discrepancy with our result can be attributed to species and/or housing differences as their recordings were performed on rat brain slices. Nonetheless, we do detect the presence of CCK-BC synaptic terminals in SH mice as seen with the overlap of VGAT/CB1R and VGAT/VGLUT3 markers (Fig. $3 A-D$ ). It is possible that these terminals are partially or fully silenced by neuromodulators. In fact, recording of DSI in this condition was only possible after bath application of carbachol (Fig. $4 G, H$ ). Altogether, our results show that CCK-BC terminals have a limited contribution to basal transmission in the DG of SH mice, and this contribution to GC inhibition is strongly enhanced by experience.

Experience-dependent remodeling of CCK-BC inputs in PE mice strongly modulate CB1R-mediated inhibition in the DG. The 50\% increase in eIPSC amplitude recorded in PE mice compared with the $\mathrm{SH}$ mice is reversed by bath application of the CB1R agonist WIN. Moreover, DSI magnitude, known to be mediated by CB1R signaling (Wilson and Nicoll, 2001; Isokawa and Alger, 2005), has a twofold increase in PE mice, demonstrating that PE enhances the contribution of CB1R-mediated inhibition in the DG. How the change in cannabinoid neuromodulation affects the computation in the circuit remains a central question to address. GC disinhibition through DSI can favor the firing of the GC and support a winner-takes-all situation, increasing activity of the sparse GCs already active. Therefore, a change in somatic inhibition from CCK + basket cell terminals expressing CB1R can favor sparsification of the entorhinal signal and increase the signal-to-noise ratio. Future work will be needed to dissect the role of the CCK-BC population in DG computation and investigate how an enhanced somatic inhibition from CCK-BCs and a change in DSI may improve learning and memory.

We found that reducing the activity of the perforant path decreased the density of the CCK + synapse in the GCL of both $\mathrm{SH}$ and PE mice (Figs. 6D,E, 7A,D). Although we did not fully silence the EC2 afferents with our viral approach (Fig. 5B,C), this result demonstrates that activity of these inputs plays an instructional role in the formation of CCK-BC synapses. It is difficult to determine the extent to which this instructional role controls the experience-dependent remodeling of CCK-BCs or the assembly of baseline CCK-BC connectivity. The plasticity at excitatory EC2-GC synapses (Fig. 1D,I) and the enhanced activity of the PE mice (Fig. $5 B$ ), prevent us from making side-by-side comparisons of the effect of the silencing in SH and PE mice. Despite these considerations, our study, along with previously published works, supports a model in which activities from upstream brain regions have an instructional role in the maturation of microcircuits along the entorhino-hippocampal circuit (Pieraut et al., 2014; Donato et al., 2017). What are the downstream effectors triggered by EC2 neurons activity? These afferents affect the neural activity of multiple cell types in the circuit, a part or all of which could act as an instructional signal for CCK-BC synapse remodeling. The signal may be activated by (1) the direct EC2 drive to CCK-BC neurons; (2) the EC2 drive to the GCs, which in turn results in the feedback excitation of the CCK-BCs; (3) the EC2 drive to the GCs, which in turn generates a retrograde signal from the GCs; or (4) the possibilty that the activity of EC2 neurons leads to the release of neurotrophins from their axon terminals in the DG. Brain-derived neurotrophic factor can be released presynaptically (Shimojo et al., 2015), and previous studies have shown that housing condition affects the release of this neurotrophin in juvenile mice (Liu et al., 2012; Novkovic et al., 2015). It is also likely that activity of the excitatory synaptic inputs onto CCK-BCs is required for CCK-BC synapse formation and plasticity (scenarios 1 or 2, above; del Pino et al., 2017). The recruitment of CCK-BC synapses can also be downstream of GC activity (scenario 3). Notably, it is possible that activity of EC afferents directly activates expression of immediate early genes in GC such as Neuronal PAS Domain Protein 4 (NPAS4), which has a role in experience-dependent remodeling of the CCK-BC network in the CA1 and DG (Bloodgood et al., 2013; Sun et al., 2020).

In light of the findings demonstrating the beneficial role of $\mathrm{PE}$ in mouse models of neurodevelopmental disorders such as Down syndrome and Rett syndrome (Lonetti et al., 2010; Begenisic et al., 2015), a better understanding of the cellular and molecular changes acting on the inhibitory network and promoted by early experiences is desirable. In the present study, we demonstrate that among the varied inhibitory synapses in the $\mathrm{DG}$, somatic CCK + innervation is adjusted in response to cortical activity. This structural plasticity is engaged during maturation of the DG in an experience-dependent manner. Future work should focus on understanding the signaling mechanisms regulating CCK+ plasticity and exploring the role of this cell type in DG computation.

\section{References}

Barak B, Zhang Z, Liu Y, Nir A, Trangle SS, Ennis M, Levandowski KM, Wang D, Quast K, Boulting GL, Li Y, Bayarsaihan D, He Z, Feng G (2019) Neuronal deletion of Gtf2i, associated with Williams syndrome, causes behavioral and myelin alterations rescuable by a remyelinating drug. Nat Neurosci 22: 700-708. 
Bartos M, Elgueta C (2012) Functional characteristics of parvalbumin- and cholecystokinin-expressing basket cells. J Physiol 590:669-681.

Begenisic T, Sansevero G, Baroncelli L, Cioni G, Sale A (2015) Early environmental therapy rescues brain development in a mouse model of Down syndrome. Neurobiol Dis 82:409-419.

Bel M, Pardi MB, Ogando MB, Schinder AF, Marin-Burgin A (2015) Differential inhibition onto developing and mature granule cells generates high-frequency filters with variable gain. Elife 4:e08764.

Bloodgood BL, Sharma N, Browne HA, Trepman AZ, Greenberg ME (2013) The activity-dependent transcription factor NPAS4 regulates domainspecific inhibition. Nature 503:121-125.

Cancedda L, Putignano E, Sale A, Viegi A, Berardi N, Maffei L (2004) Acceleration of Visual System Development by Environmental Enrichment. J Neurosci 24:4840-4848.

Chen C, Arai I, Satterfield R, Young SM, Jonas P (2017) Synaptotagmin 2 is the fast $\mathrm{Ca} 2+$ sensor at a central inhibitory synapse. Cell Rep 18:723736.

Del Pino I, Brotons-Mas JR, Marques-Smith A, Marighetto A, Frick A, Marín O, Rico B (2017) Abnormal wiring of CCK+ basket cells disrupts spatial information coding. Nat Neurosci 20:784-792.

Deng W, Mayford M, Gage FH (2013) Selection of distinct populations of dentate granule cells in response to inputs as a mechanism for pattern separation in mice. Elife 2:e00312.

Dobie FA, Craig AM (2011) Inhibitory synapse dynamics: coordinated presynaptic and postsynaptic mobility and the major contribution of recycled vesicles to new synapse formation. J Neurosci 31:10481-10493.

Donato F, Jacobsen RI, Moser MB, Moser EI (2017) Stellate cells drive maturation of the entorhinal-hippocampal circuit. Science 355:eaai8178.

Espinoza C, Guzman SJ, Zhang X, Jonas P (2018) Parvalbumin + interneurons obey unique connectivity rules and establish a powerful lateral-inhibition microcircuit in dentate gyrus. Nat Commun 9:4605.

Fasano C, Rocchetti J, Pietrajtis K, Zander JF, Manseau F, Sakae DY, MarcusSells M, Ramet L, Morel LJ, Carrel D, Dumas S, Bolte S, Bernard V, Vigneault E, Goutagny R, Ahnert-Hilger G, Giros B, Daumas S, Williams S, El Mestikawy S (2017) Regulation of the hippocampal network by VGLUT3-Positive CCK-GABAergic basket cells. Front Cell Neurosci 11:1-15.

Földy C, Lee SY, Szabadics J, Neu A, Soltesz I (2007) Cell type-specific gating of perisomatic inhibition by cholecystokinin. Nat Neurosci 10:11281130.

Frias CP, Liang J, Bresser T, Scheefhals L, Van Kesteren M, Van Dorland R, Yin Hu H, Bodzeta A, Van Bergen En Henegouwen PMP, Hoogenraad CC, Wierenga CJ (2019) Semaphorin4D induces inhibitory synapse formation by rapid stabilization of presynaptic boutons via MET coactivation. J Neurosci 39:4221-4237.

Goswami SP, Bucurenciu I, Jonas P (2012) Miniature IPSCs in hippocampal granule cells are triggered by voltage-gated $\mathrm{Ca} 2+$ channels via microdomain coupling. J Neurosci 32:14294-14304.

Hartzell AL, Martyniuk KM, Brigidi GS, Heinz DA, Djaja NA, Payne A, Bloodgood BL (2018) Npas4 recruits CCK basket cell synapses and enhances cannabinoid-sensitive inhibition in the mouse hippocampus. Elife 7:e35927.

He S, Ma J, Liu NNN, Yu X (2010) Early enriched environment promotes neonatal GABAergic neurotransmission and accelerates synapse maturation. J Neurosci 30:7910-7916.

Hefft S, Jonas P (2005) Asynchronous GABA release generates long-lasting inhibition at a hippocampal interneuron-principal neuron synapse. Nat Neurosci 8:1319-1328.

Hosp JA, Strüber M, Yanagawa Y, Obata K, Vida I, Jonas P, Bartos M (2014) Morpho-physiological criteria divide dentate gyrus interneurons into classes. Hippocampus 24:189-203.

Hosseiny S, Pietri M, Petit-Paitel A, Zarif H, Heurteaux C, Chabry J, Guyon A (2015) Differential neuronal plasticity in mouse hippocampus associated with various periods of enriched environment during postnatal development. Brain Struct Funct 220:3435-3448.

Isokawa M, Alger BE (2005) Retrograde endocannabinoid regulation of GABAergic inhibition in the rat dentate gyrus granule cell. J Physiol 567:1001-1010.

Kalogeraki E, Pielecka-Fortuna J, Löwel S (2017) Environmental enrichment accelerates ocular dominance plasticity in mouse visual cortex whereas transfer to standard cages resulted in a rapid loss of increased plasticity. PLoS One 12:e0186999.
Katona I, Sperlágh B, Sík A, Käfalvi A, Vizi ES, Mackie K, Freund TF, Sı A, Ka A, Vizi ES, Mackie K (1999) Presynaptically located CB1 cannabinoid receptors regulate GABA release from axon terminals of specific hippocampal interneurons. J Neurosci 19:4544-4558.

Kesner RP, Kirk RA, Yu Z, Polansky C, Musso ND (2016) Dentate gyrus supports slope recognition memory, shades of grey-context pattern separation and recognition memory, and CA3 supports pattern completion for object memory. Neurobiol Learn Mem 129:29-37.

Kim J, Isokawa M, Ledent C, Alger BE (2002) Activation of muscarinic acetylcholine receptors enhances the release of endogenous cannabinoids in the hippocampus. J Neurosci 22:10182-10191.

Knierim JJ, Neunuebel JP, Deshmukh SS (2014) Functional correlates of the lateral and medial entorhinal cortex: objects, path integration and local global reference frames. Philos Trans R Soc Lond B Biol Sci 369: 20130369.

Krashes MJ, Koda S, Ye CP, Rogan SC, Adams AC, Cusher DS, MaratosFlier E, Roth BL, Lowell BB (2011) Rapid, reversible activation of AgRP neurons drives feeding behavior in mice. J Clin Invest 121:1424-1428.

Lee C-TT, Kao M-HH, Hou W-HH, Wei Y-TT, Chen C-LL, Lien C-CC (2016) Causal evidence for the role of specific GABAergic interneuron types in entorhinal recruitment of dentate granule cells. Sci Rep 6:36885.

Lee SH, Soltesz I (2011) Requirement for CB1 but not GABAB receptors in the cholecystokinin mediated inhibition of GABA release from cholecystokinin expressing basket cells. J Physiol 589:891-902.

Liu N, He S, Yu X (2012) Early natural stimulation through environmental enrichment accelerates neuronal development in the mouse dentate gyrus. PLoS One 7:e30803.

Lonetti G, Angelucci A, Morando L, Boggio EM, Giustetto M, Pizzorusso T (2010) Early environmental enrichment moderates the behavioral and synaptic phenotype of $\mathrm{MeCP} 2$ null mice. Biol Psychiatry 67:657-665.

Madar AD, Ewell LA, Jones MV (2019) Temporal pattern separation in hippocampal neurons through multiplexed neural codes. PLoS Comput Biol 15:e1006932.

Mcclure C, Cole KLH, Wulff P, Klugmann M, Murray AJ (2011) Production and titering of recombinant adeno-associated viral vectors. J Vis Exp 2011(57):3348.

Micheva KD, Busse B, Weiler NC, O’Rourke NO, Smith SJ (2010) Single-synapse analysis of a diverse synapse population: proteomic imaging methods and markers. Neuron 68:639-653.

Nabel EM, Morishita H (2013) Regulating critical period plasticity: insight from the visual system to fear circuitry for therapeutic interventions. Front Psychiatry 4:1-8.

Novkovic T, Mittmann T, Manahan-Vaughan D (2015) BDNF contributes to the facilitation of hippocampal synaptic plasticity and learning enabled by environmental enrichment. Hippocampus 25:1-15.

Pelkey KA, Chittajallu R, Craig MT, Tricoire L, Wester JC, McBain CJ (2017) Hippocampal GABAergic inhibitory interneurons. Physiol Rev 97:16191747.

Pelkey KA, Calvigioni D, Fang C, Vargish G, Ekins T, Auville K, Wester JC, Lai M, Scott CMG, Yuan X, Hunt S, Abebe D, Xu Q, Dimidschstein J, Fishell G, Chittajallu R, McBain CJ (2020) Paradoxical network excitation by glutamate release from VGluT3+ GABAergic interneurons. Elife 9: e51996.

Pieraut S, Gounko N, Sando R, Dang W, Rebboah E, Panda S, Madisen L, Zeng H, Maximov A (2014) Experience-dependent remodeling of basket cell networks in the dentate gyrus. Neuron 84:107-122.

Sale A, Putignano E, Cancedda L, Landi S, Cirulli F, Berardi N, Maffei L (2004) Enriched environment and acceleration of visual system development. Neuropharmacology 47:649-660.

Savanthrapadian S, Meyer T, Elgueta C, Booker SA, Vida I, Bartos M (2014) Synaptic properties of SOM- and CCK-expressing cells in dentate gyrus interneuron networks. J Neurosci 34:8197-8209.

Shimojo M, Courchet J, Pieraut S, Torabi-Rander N, Sando R, Polleux F, Maximov A (2015) SNAREs controlling vesicular release of BDNF and development of callosal axons. Cell Rep 11:1054-1066.

Soh H, Park S, Ryan K, Springer K, Maheshwari A, Tzingounis AV (2018) Deletion of KCNQ2/3 potassium channels from PV+ interneurons leads to homeostatic potentiation of excitatory transmission. Elife 7:e38617. 
Sommeijer J-P, Levelt CN (2012) Synaptotagmin-2 is a reliable marker for parvalbumin positive inhibitory boutons in the mouse visual cortex. PLoS One 7:e35323.

Somogyi J, Baude A, Omori Y, Shimizu H, El Mestikawy S, Fukaya M, Shigemoto R, Watanabe M, Somogyi P (2004) GABAergic basket cells expressing cholecystokinin contain vesicular glutamate transporter type 3 (VGLUT3) in their synaptic terminals in hippocampus and isocortex of the rat. Eur J Neurosci 19:552-569.

Sun X, Bernstein MJ, Meng M, Rao S, Sørensen AT, Yao L, Zhang X, Anikeeva PO, Lin Y (2020) Functionally distinct neuronal ensembles within the memory engram. Cell 181:410-423.e17.

Szabo GG, Du X, Oijala M, Varga C, Parent JM, Soltesz I (2017) Extended interneuronal network of the dentate gyrus. Cell Rep 20:1262-1268.

Taniguchi H, He M, Wu P, Kim S, Paik R, Sugino K, Kvitsiani D, Kvitsani D, Fu Y, Lu J, Lin Y, Miyoshi G, Shima Y, Fishell G, Nelson SB, Huang ZJ
(2011) A resource of Cre driver lines for genetic targeting of GABAergic neurons in cerebral cortex. Neuron 71:995-1013.

Wilson RI, Nicoll RA (2001) Endogenous cannabinoids mediate retrograde signalling at hippocampal synapses. Nature 410:588-592.

Witter MP, Moser EI (2006) Spatial representation and the architecture of the entorhinal cortex. Trends Neurosci 29:671-678.

Yu J, Proddutur A, Swietek B, Elgammal FS, Santhakumar V (2016) Functional reduction in cannabinoid-sensitive heterotypic inhibition of dentate basket cells in epilepsy: impact on network rhythms. Cereb Cortex 26:4299-4314.

Yu J, Swietek B, Proddutur A, Santhakumar V (2015) Dentate total molecular layer interneurons mediate cannabinoid-sensitive inhibition. Hippocampus 25:884-889.

Yuan M, Meyer T, Benkowitz C, Savanthrapadian S, Ansel-Bollepalli L, Foggetti A, Wulff P, Alcami P, Elgueta C, Bartos M (2017) Somatostatinpositive interneurons in the dentate gyrus of mice provide local- and long-range septal synaptic inhibition. Elife 6:e21105. 